and heavier elements to be expected on this hypothesis. Considering the simplest case, that of hydrogen, let us assume that very large equal numbers of positive and negative electrons initially combine to form $\mathrm{N}+n$ positive, and $\mathrm{N}-n$ negative protons, and that the negatives immediately combine with an equal number of positives to form heavier nuclei, leaving $2 n$ positive protons to form hydrogen atoms. Since in the combination of protons to form heavy nuclei the loss of mass by "packing " is apparently small, the ratio $\frac{\text { mass of hydrogen }}{\text { total mass of all elements }}$ should be very nearly equal to $2 n / 2 \mathrm{~N}$, i.e. $n / \mathrm{N}$.

The probability that, in the fortuitous formation of $2 \mathrm{~N}$ protons, $\mathrm{N}+n$ shall be positive and $\mathrm{N}-n$ negative is $\frac{(2 \mathrm{~N}) !}{2^{2 \mathrm{~N}} \cdot(\mathrm{N}+n) ! \cdot(\mathrm{N}-n) !}$. This is a maximum when $n=0$. Call this probability for an exactly equal distribution $P$, then the probability for any other distribution is $\frac{\mathrm{P} \cdot(\mathrm{N} !)^{\frac{2}{2}}}{(\mathrm{~N}+n) ! \cdot(\mathrm{N}-n) !}$, which, in the limit when $\mathrm{N}$ is very great, reduces to $\mathrm{P} e^{-\frac{n^{2}}{x}}$. It is hence highly improbable that $n^{2}$ should be large compared with $\mathbf{N}$. If we assume that $n^{2}=\mathrm{N}$ we should get a result of the right order of magnitude. On this assumption the relative concentration of hydrogen would be $\mathrm{I} / \sqrt{\mathrm{N}}$.

Whatever may be the case in other systems, we would certainly seem to be justified in assuming that, in the solar system, all, or almost all, the atoms are of the positive nucleus type. The number of protons constituting the solar system is about $\mathbf{I} \cdot 2 \times 10^{5}$, which would give a hydrogen concentration of the order of $4 \times 10^{-29}$. As the hydrogen in the terrestrial oceans forms $8 \times 10^{-11}$ of the whole mass of the solar system, there is no need to enlarge upon the magnitude of the discrepancy. A similar argument might be applied to the other light elements formed by the combination of positive and negative protons.

The above argument may be objected to on the ground that some negative protons would certainly combine with previously formed positive complexes. As, however, about half the complex nuclei first formed would be negative, so that some of the positive protons would be lost by combination with them, we would expect these effects to balance approximately, unless we assume that, when two unequal nuclei combine, the sign of the combination is determined by that of the larger constituent. On this hypothesis it is conceivable that, if the first set of nuclei formed happened to be positive, they might so direct the course of subsequent events by annexation of negative protons, and light negative nuclei, as to lead to the existing distribution of the elements.

Royal Dublin Society,

Horace H. PoOle.

Leinster House, November 29.

\section{The Hæmoglobin Distribution on Surfaces of Erythrocytes.}

From time to time the point is brought home that factors should be discarded only when exact calculation proves them to be negligible. A case in point is the recent paper by Dr. K. Burker (Pfluger's Archiv für die gesamte Physiologie, vol. I95, p. 516). In this interesting paper it is shown that in mammals the weight of hæmoglobin per square micron of surface of the erythrocytes is apparently a constant equal to $3 \mathrm{I} \cdot 7 \times \mathrm{IO}^{-14} \mathrm{gm}$. Dr. Burker has, however, assumed that the surface area of the cells is equivalent to twice the area of a circle having for its diameter the large diameter of the cell. The general opinion is that in mammals (the camel excepted) the shape of the cells is a bi-concave disc, having a circle for its horizontal projection, and a flat bi-concave ellipse for the vertical projection of which the minor axis is about one-third of the major axis (E. Ponder, Proc. Roy. Soc. 948, p. IO2). The surface area of such an erythrocyte would then be equal to that of an ellipsoid of revolution around the minor axis. It can be shown by the integral calculus that the area of such an ellipsoid (if the minor axis is equal to one-third the major) is $\mathbf{I} \cdot 09$ times as great as that of two circles with the major axis for diameter. Dr. Burker's constant is therefore equal to $3 \mathrm{I} \cdot 7 / \mathrm{I} \cdot 09$ or $29 \times \mathrm{IO}^{-14} \mathrm{gm}$. hæmoglobin per square micron of surface of erythrocyte instead of $3 \mathrm{I} \cdot 7 \times \mathrm{IO}^{-14} \mathrm{gm}$.

Department of Physiology, Benjamin S. Neuhausen.

Johns Hopkins University, Baltimore, Md., November 24.

\section{The Local Handbook of the British Association.}

I HAVE just seen Mr. Bernard Hobson's letter in NATURE of November 4, p. 605. Mr. Hobson might have finished the quotation he gave from your review of the Hull Handbook which stated that "It approaches nearer to our ideal than that issued at any previous meeting. . . ."

Early last year Mr. Hobson wrote to me making various suggestions in connexion with the handbook, and I fancy I was able to tell him that they had all been carried out: he has now found some more. Of course no one will be able to meet the wishes of every member of the British Association in this way, but what is often forgotten is the fact that the local handbook is presented to the visitors by the local committee, and whether it is good or bad is scarcely the concern of a committee of the British Association. In our case something like $800 \mathrm{l}$. was spent in producing a book which, we knew quite well, could not possibly be read, marked, learned, and inwardly digested during the meeting, but we felt that the book might be useful for reference after the return of the members to their respective homes.

I quite agree that an index and a geological map would have been an improvement; in fact, we went to considerable trouble in the preparation of a geological map of the Riding, but the printers' strike made its publication, indexing, etc., impossible. Only a few days before the Hull meeting none of the handbook was printed off, much was still in manuscript, and it was only by working day and night that a supply was ready for the use of the members. For the benefit of future meetings of the Association, may I suggest that the editor of the handbook should not be one of the local secretaries. Each of these tasks is quite sufficient for an ordinary human being, and for one to attempt both is almost bound to court disaster.

Museum. Hull.

T. SHEPPARD.

\section{Occult Phenomena and After-images.}

Prof. ANDrade's experiments recorded in NATURE of December 23, p. 843, on the apparent movements of cardboard hands, suitably illuminated by dim light, are interesting in connexion with a phenomenon recently recounted to me by a coroner of long experience. It appears that members of the jury, when brought in to view a corpse, frequently declare that they have seen the body, sometimes of long standing, breathing. No doubt an apparent up ard 